\title{
LOS RIESGOS, LAS FUNCIONES DEL DERECHO AMBIENTAL ANTE ÉSTOS, Y SU CONTROL POR MEDIO DE ENTIDADES PRIVADAS COLABORADORAS DE LA GESTIÓN AMBIENTAL
}

[The Risks, the Role of the Environmental Law in Them, and Risk Control By Way of Private Entities That Cooperate with Environmental Management]

\author{
Christian Rojas Calderón* \\ Universidad Católica del Norte, sede Coquimbo, Chile
}

\begin{abstract}
RESUMEN
Abstract

El trabajo expone el concepto de riesgo y sus implicancias, así como los efectos que éste tiene, especialmente en el derecho ambiental. Luego se analizarán sus manifestaciones a nivel normativo y de gestión del mismo. En fin, se colocará especial atención en la configuración y régimen de las entidades colaboradoras de gestión ambiental, específicamente en el ámbito de la certificación ambiental.

Palabras Clave

Riesgo - Medioambiente - Verificación ambiental - Cooperación.

This work analyses the concept of risk, its consequences and effects, particularly within environmental law. Then its manifestations at a normative and management level will be analysed. Special attention will be given to the organisation and regime of entities cooperating in the environmental management, particularly regarding environmental certification.

\section{KEYWORDS}

Risk - Environment - Environmental verification - Cooperation.

RECIBIDo el 31 de octubre y ACEPTADO el 22 de diciembre de 2014

* Licenciado en Ciencias Jurídicas por la Universidad de Valparaíso; magíster en ciencia jurídica y doctor en derecho por la Pontificia Universidad Católica de Chile. Profesor asistente de la Facultad de Ciencias Jurídicas, Universidad Católica del Norte (Chile). Dirección postal: Larrondo 1281, Coquimbo, Chile. Correo electrónico: chrojas@ucn.cl Este trabajo forma parte del proyecto del Ministerio de Economía y Competitividad de España, titulado: "Estrategias reguladoras y de aplicación del derecho público más allá del aparato administrativo del Estado” (DER 201239449 C02 01), del cual el autor es investigador asociado.
\end{abstract}




\section{EL RIESGO, PRESENTE ORDINARIAMENTE EN NUESTRAS VIDAS}

\section{Preliminar.}

Qué duda cabe, vivimos rodeados de situaciones de riesgo, que el hombre ha creado y crea regularmente para atender la incertidumbre y los peligros. Por lo mismo, este factor es tomado más o menos en consideración desde distintos acercamientos disciplinarios.

En efecto, las cuestiones desde la órbita fáctica o desde cualquier otra vinculada con los riesgos, resulta de hondo calado y así ha sido asumido por el conocimiento desde diferentes órbitas; por lo mismo, este trabajo de contenido esencialmente jurídico sólo podrá decir algunas cosas generales, básicamente en el ámbito conceptual, para luego explicar su manifestación en lo propiamente jurídico y en particular en el jurídico-ambiental, específica área de análisis de éste.

En este sentido, conviene por tanto señalar -y se ha aceptado- que conceptualmente los riesgos son aquellos "que no tienen un origen natural ajeno a la intervención humana, sino que se debe precisamente a la acción del hombre que va precedida así de una decisión, de la que se puede ser más o menos consciente en función del conocimiento que se tenga sobre los posibles efectos, pero decisión humana al fin"'. De hecho, se la define también ya más comúnmente como un daño futuro cuya producción es incierta, y que constituye una consecuencia de la acción humana ${ }^{2}$.

Se trata, en efecto, de situaciones auto-producidas, creadas por los seres humanos, que dependen en última instancia de una decisión y por consiguiente, es posible dotarlas de configuración y/o estructura, y que se caracterizan por una escasa probabilidad aunque también por los elevados daños una vez que éstos se producen ${ }^{3}$.

Luego, resulta evidente que hay riesgos asociados a esas actividades vinculadas muy directa e intensamente en la vida ordinaria de las personas, como son los derivados de la medicina, la industria automotriz, la farmacéutica, la actividad financiera, la construcción, la alimentaria ${ }^{4}$, la minera, la fabril

${ }^{1}$ Esteve Pardo, J., Técnica, riesgo y derecho (Barcelona, Ariel, 1999), p. 29.

${ }^{2}$ Moya Marchi, F., El principio de precaución. Un estudio sobre el modelo europeo de control de riesgo (Santiago, Thomson Reuters LegalPublishing, 2014), p. 24.

${ }^{3} \mathrm{MAy}, \mathrm{S}$., Nuevos riesgos, seguridad y prevención, sobre la transformación del Estado moderno y su forma de actuación jurídica, en PÉREz Alonso, E. y otros (editores), Derecho, globalización, riesgo y medio ambiente (Valencia, Tirant lo Blanch, 2012), pp. 306 309. Siguiendo este mismo orden de ideas, el tema que surge de inmediato es el de la responsabilidad del sujeto autorizado y también del autorizante; lo que se deja simplemente enunciado, pues se trata de temas que escapan al marco específico de este trabajo pero que en el futuro serán abordados.

${ }^{4}$ En este ámbito se destaca especialmente el "Programa Conjunto FAO/OMs sobre 
o industrial en general, entre muchas otras. A todas ellas les une algo, y es el hecho cierto que son actividades desarrolladas o dirigidas estrictamente por el hombre, y que plantean desafíos múltiples y permanentes para los gobiernos de países desarrollados y en desarrollo; y ante ellos, en general, tanto los científicos o expertos como los políticos o los operadores se sienten desorientados ante la toma de cualquiera decisión, pues aquellos se presentan como múltiples y multidimensionales, con diferentes niveles de profundidad dependiendo del grupo o intereses generales o específicos que se pretendan tutelar, no resultando extraño que se tomen varias decisiones sectoriales por distintos actores respecto de ellos, algunas de las cuales pueden ser -es común- hasta contradictorias si es que no se preserva la debida coordinación. Ello hace que al enfrentar un riesgo y sobre todo al enfrentar la toma de decisiones en un escenario de riesgos, sea prudente concentrarse en las pocas cosas que más importan como ciudadanos, padres, conductores, pacientes, consumidores, activistas, trabajadores, investigadores científicos u operadores jurídicos 5 . En caso contrario, sobre todo por parte de las autoridades estatales, lato sensu pueden tomarse decisiones donde los errores no resultan inocuos, lo que ocurre especialmente cuando no se consideran todos los factores, reaccionando frente a protestas públicas sin tener presente los efectos colaterales o secundarios de sus decisiones, o respondiendo frente a temores infundados y habitualmente fugaces ${ }^{6}$.

En fin, parece que en el ámbito jurídico, estos riesgos se asocian a diversas clases de decisiones: unas de carácter legal, otras de carácter regulatorio en un nivel inferior, otras con un contenido decisorio-autorizatorio, y otras derivadas de las actividades sancionatorias a que da origen en distintos niveles. Y todas ellas operan en distintas etapas cronológicas, así como en diferentes estadios de la actividad humana.

\section{El origen tecnológico de los riesgos y sus proyecciones jurídicas.}

Luego de lo señalado, para avanzar en torno a los objetos de este trabajo, es preciso sostener que los riesgos, y con ello su conceptualización y configuración, se adscriben inequívocamente a la técnica y la ciencia. Los riesgos, al menos tal y como están perfilados en su concepto, tienen un origen siempre

Normas Alimentarias", que elabora continuamente documentos en miras de la inocuidad alimentaria como elemento fundamental de la salud pública y de promoción del desarrollo económico. La información se encuentra disponible entre otros sitios en www.codexalimentarius.net [23 de mayo de 2014]

${ }^{5}$ Fischhoff, B. - Kadvany, J., Riesgo, una breve introducción (traducción de P. Ventura, Madrid, Alianza Editorial, 2013), pp. 16-17.

${ }^{6}$ Sunstein, C., Riesgo y razón, seguridad, ley y medioambiente (traducción de J. M. Lebrón, Buenos Aires, Katz, 2006), p. 19. 
tecnológico. Justamente en virtud de ello se traza la diferencia, entre riesgo y peligro; lo que se asocia a planteamientos y desarrollos esencialmente constructivistas y sociológicos donde Beck y Luhman son sus pioneros, y que suponen un daño en cuanto factor de resultado. Así, si el daño se atribuye o es consecuencia de una decisión, estamos ante un riesgo; y si éste se atribuye al entorno, entonces es consecuencia de un peligro ${ }^{7}$.

Más concretamente a nuestra temática, el peligro tiene un origen natural, son peligros naturales, de manera tal que no hay intervención humana en la generación de los peligros; mientras que en el caso del riesgo, éste tiene un origen tecnológico. Por lo que detrás de un riesgo siempre hay, ineludiblemente, una tecnología, y detrás de una tecnología siempre hay un conjunto de decisiones humanas. No somos, por tanto, responsables frente a los peligros de origen natural, pues no los hemos generado, pero sí que somos responsables frente a los riesgos; en consecuencia los peligros no constituyen en principio materia para el derecho.

Los riesgos en cambio sí, y de manera central; es más, el hombre primero y luego cualquier sociedad desde sus inicios debe hacerle frente a un medio natural que le es hostil, que le ofrece una serie de limitaciones, que presenta una serie de peligros y esos peligros siempre, ineludiblemente, se han venido combatiendo, neutralizando y superando, a través de la tecnología ${ }^{8}$. A partir del desarrollo industrial y tecnológico, que ha permitido superar toda una serie de peligros (frío, hambre, distancias, enfermedades y un largo etcétera) a los cuales ya afortunadamente no se está expuesto, y otros que acosaban antiguamente, éstos han sido superados en las sociedades cada vez más avanzadas producto precisamente del desarrollo tecnológico y de la complejización de la vida en comunidad. Pero junto con ello, donde se han sucedido superaciones y avances permanentes mediante el desarrollo y aplicación de alguna tecnología, invariable e inevitablemente se han generado riesgos correlativos.

Así, los peligros derivados de la falta de alimentación han sido superados mediante el desarrollo de una industria: la alimentaria; los peligros derivados de la falta de energía, o los problemas que podíamos encontrar frente a heladas o fríos, es decir, las necesidades de energía han sido también superadas mediante una industria: la energética; y lo mismo puede decirse en el plano sanitario, en el plano de las telecomunicaciones, en el plano farmacológico o el plano del transporte en sus distintas modalidades. El problema está en

${ }^{7}$ Martínez García, J. I., Pensar el riesgo, en diálogo con Lubman, en Pérez Alonso, E. y otros (editores), Derecho, globalización, riesgo y medio ambiente (Valencia, Tirant lo Blanch, 2012), p. 331.

${ }^{8}$ Esteve Pardo, J., El derecho del medio ambiente como derecho de decisión y gestión de riesgos, en Revista Electrónica de derecho de la Universidad de La Rioja, 4 (2012), pp. 8-9. 
que todas estas tecnologías no son inocuas; pues son unas tecnologías que, en principio, preferimos a los peligros que con ellas se pretenden superar, pero que generan también riesgos -y muy serios en muchos casos-, que derivan de cada una de las dichas industrias. Y en efecto, todo este desarrollo tecnológico e industrial genera una gran variedad de riesgos y muchos de ellos, son riesgos que constituyen el objeto de atención fundamental del derecho y en especial del derecho ambiental por la afección, casi certera, que estas tecnologías generan para el entorno o medio ambiente.

Luego, también resulta evidente que el consenso social sobre el progreso industrial y el progreso tecnológico se ha roto en tiempos recientes en el mundo y ha entrado en una cierta crisis en la actualidad, generándose movimientos sociales que han terminado incidiendo en decisiones de la autoridad pública, política al fin'; y en medio de esa ruptura es donde se sitúa, entre otros y sobremanera, la disciplina del derecho ambiental. En efecto, en cualquier caso que se plantee un conflicto medioambiental, que ordinariamente pueda suscitarse en torno a una gran obra pública, a una instalación industrial, a una operación minera o urbanística, entre tantas otras, se reproduce esa ruptura social en torno al progreso material y técnico; de tal manera que en cualquier conflicto hay partidarios de que esa instalación se autorice o esa obra se ejecute porque eso significa desarrollo económico, generación de puestos de trabajo, progreso industrial, es decir, generación de riqueza; mientras que habrá otro sector u otra posición que tendrá un planteamiento mucho más crítico y pondrá de manifiesto los aspectos negativos, el lado oscuro de ese progreso tecnológico, de esa actividad industrial o esa transformación del entorno para las personas y su medio ambiente.

Como se señaló anteriormente, los riesgos se asocian a daños y a su atribución, lo que genera responsabilidad; pero también, en virtud de ellos, es posible prevenirlos en lo cual los poderes públicos y el derecho -como instrumento de ellos- actúa ya no reactivamente sino que activamente interviniendo en diferentes aspectos de la vida.

\section{La problemática decisional del derecho ante las incertidumbres de la iencia ${ }^{10}$.}

Luego de los reconocimientos hechos, conviene señalar que el sistema

${ }^{9}$ Se recuerda especialmente el episodio del "telefonazo" una vez aprobada la central Barrancones (térmica), en cuya virtud se retiró dicho proyecto de manera voluntaria, pese a tener una resolución de calificación ambiental calificada favorablemente en primera fase.

${ }^{10}$ Se sigue en esto la perspectiva propuesta por Esteve Pardo, J., El desconcierto del Leviatán. Politica y derecho ante las incertidumbres de la ciencia (Madrid, Marcial Pons, 2009), pp. 1-20; y Esteve Pardo, J. - Tejada Palacios, J., Ciencia y derecho. 
jurídico en el que estamos instalados, en todos sus elementos -órganos e instancias, procedimientos y procesos, y referencias conceptuales-, se orientan a la decisión que es, en definitiva, la solución de la incertidumbre y la controversia. Sin embargo, esa certidumbre, esa seguridad jurídica al fin, se ve presionada y conmovida por la expansión de la incertidumbre, en un escenario donde el derecho pretende imponer su dominio y su sistema de certezas, pero que no resulta indemne ante la incertidumbre y complejidad -sobre todo científica y tecnológica-, que con frecuencia lo desborda y que genera efectos en esa certeza; por lo mismo el derecho debe desarrollar estrategias para abordarla y sobre todo para cumplir su función esencial: decidir.

En efecto, la ciencia está adquiriendo una extraordinaria relevancia para el derecho, y son varias las causas de ese creciente protagonismo. Entre ellas se destacan las siguientes.

En prim er término, hoy la ciencia es posiblemente la principal fuente de generación de incertidumbres, sobre todo derivada de sus avances y de la complejidad del conocimiento. En s e gu n d o lugar, el propio conocimiento científico se reconoce incierto en muchos de los frentes en que avanza, cambiando de ser ciencias exactas a ciencias probabilísticas. La t e r c e r a, deriva precisamente den ese cambio de postura de la ciencia que necesariamente descoloca a las otras disciplinas del conocimiento que se miraban en ella para asentar sus propias certidumbres, algunas de las cuales no se han dado cuenta o no se han querido percatar de este giro ${ }^{11}$. Y en c u a r to lugar, la imparable presencia de la ciencia en la propia agenda de los temas que centran el debate político y la controversia jurídica, una agenda cada vez más dominada por cuestiones suscitadas desde foros científicos: tales como cambio climático, energía, células madre, valoración científica de riesgos para el medio ambiente, régimen de patentes farmacéuticas, organismos genéticamente modificados, alimentos transgénicos, entre tantos otros.

Es así como la política y el derecho se ven cada vez más, con cuestiones que tiene en su núcleo un marcado componente científico. La consecuencia de este planteamiento es que se están produciendo con una frecuencia creciente y preocupante, decisiones políticas y jurídicas muy relevantes en materias en las que existe una reconocida incertidumbre científica.

La nueva división de poderes (Madrid, Fundación Coloquio Jurídico Europeo, 2013), pp. 11-32.

${ }^{11}$ Que por lo demás se había descrito hace tiempo ya Kunn, T. S. La estructura de las revoluciones cientificas (traducción de A. Costín, Santiago, Fondo de Cultura Económica, 2000), pp. 33-34. Su primera edición en inglés fue de 1962. 


\section{LA CONSTRUCCIÓN COHERENTE DEL DERECHO AMBIENTAL}

A PARTIR DEL ANÁLISIS SISTÉMICO

\section{Preliminar.}

Aplicando el análisis metodológico que se encuentra detrás de la idea de sistema, primero al derecho, luego al derecho Administrativo y finalmente a una de las disciplinas conexas a éste como es el caso del derecho ambiental, es posible formular relaciones, intercalamientos y guías que posibilitan generar productos a lo menos sistematizadores o mejor aun dogmáticos, más coherentes en aras del ordenamiento, comprensión, aplicación y al final solución de controversias jurídicas ${ }^{12}$. Habida cuenta de su trascendencia, enseguida cabe señalar que esa fórmula de entendimiento alcanza a muchas de las cuestiones que se plantean a diario en su aplicación, entre las cuales hay vasos comunicantes. Por ello, la dogmática de la disciplina del derecho Administrativo -como disciplina matriz o cabecera de grupo-y del derecho ambiental -como especialidad autónoma de éste-, ha de construirse reflexionando sobre las instituciones y categorías fundamentales que constituyen un reflejo del sistema jurídico, comprendido dentro de la totalidad.

Por consiguiente a la sistematización científica del derecho le cabe cumplir una triple función: $i$ ) Por un lado práctica; en cuanto sirve de guía y apoyo a la jurisprudencia; ii) Luego, dogmática; para responder a las cuestiones singulares desde una perspectiva sistemática, al tiempo que se revisan, comparan y reconstruyen los conceptos; iii) En fin, política, puesto que un sistema bien elaborado sirve de "mapa" u orientación para la política legislativa, evitando disfunciones, solapamientos o contradicciones, así como un innecesario activismo legislativo.

Esta perspectiva sistemática no es sinónimo de codificación, sino al contrario, de indicador o guía para un ordenamiento en continuo movimiento.

\section{El sistema del derecho ambiental.}

Enseguida, siguiendo en esto claramente a Bermúdez, el derecho ambiental chileno es principalmente derecho administrativo especial ${ }^{13}$, ya autónomo por la configuración de instituciones propias, sin perjuicio de lo cual siempre puede hacerse una reconducción a normas e instituciones de la disciplina matriz indicada, y como señala él mismo, esto es así porque en

${ }^{12}$ Schmidt Assmann, E., La teoría general del derecho administrativo como sistema (traducción de M. Bacigalupo y otros. Madrid, Marcial Pons, 2003), pp. 1-50, en Chile, de modo específico: Vergara Blanco, A., Principios y sistema del derecho Minero (Santiago, Editorial Jurídica de Chile, 1989), pp. 17-42.

${ }^{13}$ Bermúdez Soto, J., Fundamentos de derecho ambiental (Valparaíso, Ediciones Universitarias de Valparaíso, 2007), p. 10. 
el derecho Administrativo encuentra su centro de gravedad ${ }^{14}$. En el mismo sentido, se afirma por Varela el carácter esencialmente público del derecho ambiental, toda vez que la política ambiental del Estado es comprensiva de los instrumentos jurídicos a través de la cual se concreta, que están destinados a ejecutarla con carácter vinculante tanto para gobernantes como para gobernados ${ }^{15}$.

En virtud de lo ya dicho acerca de la formulación sistémica del derecho en general, y la consecuencia que el derecho Administrativo sea ciencia matriz respecto del derecho ambiental (que es una rama especializada), es posible afirmar que la matriz disciplinar ${ }^{16}$ de esta última disciplina se asienta sobre lo siguiente: $i$ ) los principios y conceptos técnicos del derecho ambiental; ii) la fundamentación constitucional de la protección ambiental; iii) los instrumentos que el ordenamiento jurídico ha consagrado para la protección ambiental; y $i v$ ) un sistema especial de responsabilidad ambiental ${ }^{17}$.

Ahora bien, en esa situación, el marco jurídico particular del derecho ambiental -aquello que lo define y caracteriza del modo señalado- puede verse en algunos casos enfrentado a verdaderos problemas sin solución específica en su regulación, que generan dificultades prácticas pero también dogmáticas, al no haberse desarrollado normativamente algunos aspectos por parte de sus fuentes específicas lo que sin embargo resulta explicable dada su reciente existencia en cuanto tal. En el caso chileno, ello es especialmente significativo toda vez que tiene una ley general y básica -la Ley de bases generales del medio ambiente-, en tanto que el resto de su normativa se ha concretado en su mayoría en normas de carácter reglamentario, como reglamentos propiamente tales, normas infra reglamentarias, o incluso por medio de norma particulares ${ }^{18}$.

No obstante ello, es posible resolver dichas problemáticas, partiendo

${ }^{14}$ Bermúdez Soto, J., Fundamentos de derecho ambiental (Valparaíso, Ediciones Universitarias de Valparaíso, 2014), p. 36. Este libro corresponde a una segunda edición del que fuera publicado por el mismo autor el 2007, pues comprende una sustantiva ampliación, actualización y corrección de la primera edición, lo que se comprende considerando los significativos cambios legislativos ocurridos entre ambas obras.

${ }^{15}$ Varela del Solar, J., Derecho ambiental como derecho público. Instrumentos de la politica ambiental, en Actualidad Jurídica No 22 (2010), p. 385.

${ }^{16}$ En general, matriz disciplinar es el punto primordial en que se concentran al menos potencialmente todas las teorías, conceptos y leyes con que opera una comunidad científica. GonzÁlez NAVARro, F. La teoría general de sistemas como matriz disciplinar y como método jurídico, en Persona y Derecho, 21 (1989), p. 64.

${ }^{17}$ Bermúdez Soto, Cit. (n. 13), p. 9.

${ }^{18}$ Para una visión completa de la normativa sistematizada -aunque desactualizada por la fecha de edición, igualmente vale la pena revisar-, Bermúdez Soto, J. Código de Medio Ambiente (Santiago, LegalPublishing, 2007), in totum. 
desde la idea -ya esbozada- de "sistema", que acude en ayuda de este estatuto normativo a fin de completarlo en sus lagunas por medio de la legislación que naturalmente -por la naturaleza jurídica de sus instituciones- es llamada a complementarla. Obviamente, esto se encuentra íntimamente unido al carácter supletorio de las ciencias (jurídicas) matrices, a partir de las instituciones y categorías conceptuales que desarrollan con respecto a sus especialidades, como sería el caso de la disciplina del derecho Administrativo -como disciplina matriz o cabecera de grupo-, con respecto a la disciplina del derecho ambiental-como especialidad o autonomía-, en tanto sea pertinente para los fines de dar solución práctica o dogmática a desarrollos incompletos o derechamente a vacíos regulatorios ${ }^{19}$.

Consecuencialmente, es posible afirmar que el derecho administrativo es el derecho co mún en todo el ámbito público -en el mismo plano que lo puede ser el derecho civil en el ámbito privado-, al cual deben conectarse debidamente todas sus disciplinas derivadas y ya autónomas de éste, como el derecho de minería, el derecho eléctrico, el derecho de las telecomunicacio-

${ }^{19}$ En general es posible entender por suple toridad la aplicación en segundo grado de normas distintas a las que regulan principalmente un determinado supuesto de hecho, para perfeccionar las previsiones de la normativa principal o primeramente llamada a regular y solucionar la situación; así, la aplicación supletoria de normas secundarias respecto de aquellas que primeramente son llamadas a brindar soluciones jurídicas es manifestación incontrovertible de sistemática, lo que implica un procedimiento o método de interrelación de derechos que, conectados naturalmente unos con otros, se complementan. Ello supone ciertos requisitos, a saber: $i$ ), existencia de una normativa principal incompleta; $i$ ), existencia de una norma distinta de un cuerpo común o matriz que resulte aplicable al punto controvertido; iii), aplicación de una norma secundaria -que no se encuentra en el cuerpo normativo principal-, respetando los principios jurídicos del derecho suplido o completado en una escala de concreción de mayor a menor cercanía con el punto regulado que se pretende suplir; iv), carácter jurídico positivo y escrito, tanto de la norma suplida como de la supletoria; y $v$ ), aplicación del derecho matriz correspondiente a la disciplina especial suplida - por ejemplo el derecho administrativo respecto al derecho de Aguas o respecto del derecho ambiental-, con preferencia con respecto a otros derechos comunes, correspondientes a sectores diferentes del derecho. De este modo, las pretensiones de aplicabilidad de disposiciones correspondientes a otros sectores del sistema jurídico, vulnerando la división público privado (ius publicum - ius privatum), que registra no sólo nuestra tradición jurídico continental de derecho legislado, sino que normas jurídicas generales o especiales del ordenamiento chileno, y principios del derecho diferentes en uno y otro sector; no resulta lógicamente admisible atendidas las claras y graves diferencias entre ellos. MoLero Manglano, C., La supletoriedad del derecho común en el derecho del trabajo (Madrid, Instituto de Estudios Políticos, 1975), p. 34; en el mismo sentido, aunque aplicándolo al derecho administrativo: Vergara BLANCO, A., El derecho administrativo como sistema autónomo. El mito del Código Civil como "derecho común" (Santiago, Abeledo Perrot, 2010), pp. 29-66. 
nes, el derecho de aguas y, por cierto, el derecho ambiental. En este mismo sentido Cordero sostiene el carácter unitario del sistema administrativo, que impone que los entes potestados administrativamente "tengan sistemas normativos comunes que operen como elementos adecuados de garantía para los ciudadanos que se relacionan con habitualidad con ellos, además de dotar de criterios comunes al sistema legal que evite discriminaciones arbitrarias" ${ }^{20}$. Hay que tener presente, no obstante, que el derecho administrativo y sus desgajes, en cuanto sistema jurídico concebido bajo una idea ordinamental, debe mirar siempre a la Constitución a la cual se someten todos los órdenes particulares.

\section{LOS MEDIOS O INSTRUMENTOS DE PROTECCIÓN}

\section{AMBIENTAL EN GENERAL}

\section{Antecedentes.}

Dicho lo anterior, y que dice relación con la perspectiva que se emplea en el análisis y que, al mismo tiempo, permite trazar la matriz disciplinar del derecho ambiental -siguiendo claramente a Bermúdez-, corresponde acometer en general los medios, formas o maneras en que se asume la finalidad de protección ambiental.

En ello, hay que considerar primeramente que los Estados han asumido, en diverso grado y a través de distintas formas, la "cuestión ambiental" como una función pública, que se concreta en tareas en miras de la protección ambiental cuya manifestación es variada, pues en efecto, es posible reconocer actividad formal o jurídica propiamente tal y actividad material por parte de la Administración Pública en tal sentido, sea general sea sectorial. De este modo, se ha determinado como manifestación de la finalidad de protección ambiental, la actuación en vía instrumental bajo tres clases, que constituyen herramientas o instrumentos de gestión ambiental, a saber: la Política ambiental, la Economía ambiental y el derecho ambiental.

Esta tercera herramienta, que utiliza el poder jurídico-público para llevar adelante la finalidad de protección ambiental, puede ser definido como "el conjunto de disposiciones que tienen por objeto la protección de los elementos del patrimonio ambiental, con el fin de asegurar las condiciones que permitan la subsistencia humana y la mejora de la calidad de vida de las personas así como de las generaciones futuras"21.

${ }^{20}$ Cordero Vega, L., La supletoriedad en la Ley de bases de procedimiento administrativo, en AA. VV., Acto y procedimiento administrativo. Actas de las Segundas Jornadas de derecho administrativo (Valparaíso, Ediciones Universitarias de Valparaíso, 2007), pp. 54-55.

${ }^{21}$ BermúdeZ, J., cit. (n. 13), p. 34; Bermúdez, J., cit. (n. 14), p. 35. 


\section{Los órdenes normativos.}

El derecho ambiental se encuentra normativamente configurado a partir de una regulación estructurada constitucionalmente, una normativa legal general y básica del sector, otras normas legales especiales, y luego el conjunto de normas reglamentarias que concretan sus mandatos. Ello, al mismo tiempo, permite sostener que, tanto sustantiva como procedimentalmente, el derecho ambiental tiene una naturaleza jurídico-pública y especialmente administrativa ${ }^{22}$.

Lo antes dicho, se concreta en el primer ord en, por medio del reconocimiento en la Constitución Política de la República, que se encuentra en la consagración a nivel constitucional de la protección del medio ambiente en el artículo $19 \mathrm{~N}^{\circ} 8 \mathrm{CPol}$. del modo que indico: "La Constitución asegura a todas las personas: $/ 8^{\circ}$. El derecho a vivir en un medio ambiente libre de contaminación. Es deber del Estado velar para que este derecho no sea afectado y tutelar la preservación de la naturaleza. / La leypodrá establecer restricciones especificas al ejercicio de determinados derechos o libertades para proteger el medio ambiente".

En consecuencia, por medio de dicha disposición se establece por un lado un derecho subjetivo público consistente en el "derecho a vivir en un medio ambiente libre de contaminación"; y, por otro, un deber estatal de "tutelar la preservación de la naturaleza”. Luego, se establece una limitación típica al derecho de propiedad lo que en el $\mathrm{N}^{\circ} 24$ del mismo artículo y cuerpo normativo, que se concreta en la posibilidad que la ley especifique esas limitaciones a la propiedad por la función social que le corresponde derivada en este caso de la exigencia de "conservación del patrimonio ambiental"23.

El segundo orden normativo, lo encontramos en la Ley de bases generales del medio ambiente, que tiene un objeto declarado de su artículo 1 que señala: "El derecho a vivir en un medio ambiente libre de contaminación, la protección del medio ambiente, la preservación de la naturaleza y la conservación del patrimonio ambiental se regularán en las disposiciones de la presente ley, sin perjuicio de lo que otras normas establezcan sobre la materia".

Como se puede apreciar, es una norma de gran relevancia, pues fija principalmente el ámbito competencial de la citada ley general a nivel regulatorio. Sin perjuicio de esa primera reflexión, enseguida conviene sostener que aquello en el texto de la ley se concreta en realidad estableciendo básicamente lo siguiente: $i$ ) La fijación de un catálogo de definiciones de

${ }^{22}$ VARELA, J. (n. 15), p. 410.

${ }^{23}$ BERMúdEZ, J., cit. (n. 13), pp. 71-72; y BERMúdeZ, J., cit. (n. 14), pp. 113-117, en el mismo sentido, Guzmán Rosen, R., La regulación constitucional del ambiente en Chile. Aspectos sustantivos y adjetivos. Historia, doctrina y jurisprudencia (Santiago, Abeledo Perrot, 2010), pp. 96-105. 
conceptos y principios de naturaleza ambiental; ii) Una institucionalidad orgánica ambiental; iii) La incorporación del Sistema de Evaluación de Impacto ambiental como mecanismo principal de gestión ambiental; y $i v$ ) Un sistema de responsabilidad ambiental.

Conviene, dada la temática precedente -del riesgo-, señalar que éste se conecta normativamente de manera directa con el derecho ambiental, toda vez que la finalidad del derecho subjetivo público antes referido, es conceptualmente desarrollado en el artículo 2 letra m) de la ley general al definir lo que se debe entender por medio ambiente libre de contaminación, a saber: "[...] aquél en el que los contaminantes se encuentran en concentraciones y periodos inferiores a aquéllos susceptibles de constituir un riesgo a la salud de las personas, a la calidad de vida de la población, a la preservación de la naturaleza o a la conservación del patrimonio ambiental.

Junto a las anteriores normas, pero ya en un tercer orden figuran una serie de leyes con contenido ambiental, que corrigieron o complementaron la ley general -con un origen importante en recomendaciones de la Organización para la Cooperación Económica y el Desarrollo-, lo que dio lugar a la dictación de la Ley $\mathrm{N}^{\circ} 20.417$ de 2010, de reforma de la Ley de bases generales, donde se estableció básicamente lo siguiente: una potestad política, de diseño institucional, y regulatoria: entregada al Ministerio del Medio Ambiente, con una subsecretaría, seis divisiones y secretarías regionales ministeriales con representación en cada región del país; un Consejo de Ministros para la Sustentabilidad; un sistema de evaluación ambiental por medio del: entregado al Servicio de Evaluación ambiental que sustituye a la Comisión Nacional del Medio Ambiente; un sistema de fiscalización, entregado a una Superintendencia del Medio Ambiente.

Adicionalmente, cabe sumar un claro sistema de revisión judicial por los Tribunales ambientales (con su Ley No 20.600 de 2012) con área competencial específica, donde anteriormente sólo existía participación de la justicia ordinaria; y un Servicio de Biodiversidad y Áreas Protegidas del Estado con proyecto de ley aun en trámite.

En fin, el cua r to ord e n es el de los instrumentos normativos que dan vida, desarrollan y particularizan al derecho ambiental a nivel reglamentario, con especial incidencia de normas de calidad y normas de emisión ${ }^{24}$.

${ }^{24}$ Es rasgo esencial la evolución y actualidad de la institucionalidad medioambiental, en efecto, el establecimiento de la agenda ambiental en términos institucionales se ha desarrollado en Chile desde 1984, fecha en que se creó una Comisión Interministerial de Ecología, institución de integración interministerial cuyo objetivo fue asesorar al Ejecutivo en el desarrollo de aquellas acciones generales del gobierno vinculadas a la protección del medio ambiente y a la conservación de los recursos renovables. En abril de 1990, el Gobierno de Patricio Aylwin, creo la Comisión Especial de Descon- 
Lo antes dicho tiene significancia para nuestra temática específica, toda vez que resuelta significativo el rol que tienen los niveles normativos en, por un lado, la determinación del riesgo permitido, y, por otro, la gestión de dicho riesgo.

\section{LOS INSTRUMENTOS DE INTERVENCIÓN DE PODERES PÚBLICOS EN LA ACTIVIDAD PRIVADA CON INCIDENCIA MEDIOAMBIENTAL}

\section{Técnicas de intervención administrativa.}

Las técnicas de intervención son el conjunto de medios que la Administración utiliza para actuar bajo cualquiera de las modalidades admitidas por el ordenamiento jurídico, expresando el contenido de la intervención ${ }^{25}$.

taminación de la Región Metropolitana, cuyo principal aporte fue la elaboración de un Plan de Descontaminación para la región, Comisión que estaba integrada también por un Comité de carácter interministerial. En septiembre de ese año, el Gobierno sustituyó la Comisión Nacional de Ecología por la Comisión Nacional del Medio Ambiente (Decreto supremo № 240/90), que trabajó también sobre la base de un comité interministerial. Con la emisión de la Ley de bases generales en 1994, se consolidó en Chile el modelo coordinador y transversal, que se había promovido desde el modelo del "Proyecto de Ley básica de protección ambiental y promoción del desarrollo sostenible" de 1993, elaborado para América Latina por el Programa de las Naciones Unidas para el Medio Ambiente. Los objetivos declarados de la nueva institucionalidad eran garantizar la coordinación de todo el sector público; reconocer las competencias de los servicios y ministerios en la materia; y contar con la presencia política indispensable en su integración. Así, la institucionalidad ambiental diseñada por la Ley de bases generales descansó en un modelo transversal y coordinador; en la conveniencia práctica de mantener la institucionalidad preexistente; la generación de una función coordinadora que integre las visiones sectoriales; y la descentralización regional, plasmada en la creación de las Comisiones Regionales del Medio Ambiente. Sin embargo, luego de catorce años de funcionamiento, se formularon una serie de críticas a este diseño, dentro de las que es posible destacar desde el análisis político institucional, las que siguen, las dificultades que presenta una institución transversal en una Administración pública vertical; la incomprensión jurídica y de gestión del concepto de coordinación; la intervención de la autoridad política en cuestiones que son eminentemente de decisión técnica; la existencia de asimetrías de información en diversos sentidos; a nivel regional, la institucionalidad ambiental ha sido contradictoria con el modelo transversal; la fiscalización es dispersa e inorgánica lo cual genera muchos costos; la gestión local en materia ambiental es débil; la utilización de los instrumentos de gestión ha sido desequilibrada (mucho Sistema de Evaluación de Impacto ambiental, pocas normas); y la normativa ambiental sectorial es, en gran medida, definida por cada sector. Todo ello dio origen a las leyes $\mathrm{N}^{\text {os }} 20.417$ de 2010, de modificación a la institucionalidad y 20.600, de 2012.

${ }^{25}$ Villar Ezcurra, J. L., Derecho administrativo especial (Madrid, Civitas, 1999), p. 38 . 
Siguiendo esta idea, las técnicas de intervención encuentran su fundamento en potestades administrativas especificadas, concretándose de este modo los títulos de intervención, que son orientados por las formas o modalidades que ésta alcanza. De este modo, las técnicas explican có mo intervienen los sujetos titulares de potestades administrativas, a través de sus potestades específicas; de las que emanan en general autorizaciones, inspecciones, sanciones, prohibiciones, subvenciones.

Luego, sin perjuicio de la descripción sucinta anterior, en términos muy amplios y a fin de poder ofrecer un panorama suficientemente amplio sobre las formas de cada tipo de intervención administrativa, se indica un conjunto de técnicas en los ámbitos referidos del que se analizará sólo una de ellas ${ }^{26}$.

\section{Concreción en la antigua policía administrativa.}

Que tradicionalmente es la forma de intervención que más técnicas utiliza, surtiendo al resto de las actividades por medio de las siguientes, sin agotar todas las posibilidades.

Ella comprende en primer lugar la regulación lato sensu de las actividades. La misma tiene esencialmente carácter imperativo, e implica la utilización de la potestad normativa a través de la cual se ordena la actividad de los particulares estableciendo obligaciones y prohibiciones; dentro de ella es posible reconocer como una variante a las autorizaciones, que bajo distintas denominaciones (licencias, permisos, mercedes, derechos) hace referencia a la remoción de obstáculos para el ejercicio de una actividad o el disfrute de algún derecho, habitualmente sujeto a procedimientos concesionales; también las co m p robacion es, que se concreta en certificaciones, homologaciones y verificaciones a través de las cuales se constata documentalmente el cumplimiento de ciertos requisitos exigidos por la regulación de una actividad; y las ablacio nes referidas fundamentalmente a derechos patrimoniales sea aumentando las cargas existentes o imponiendo una nueva.

En segundo término, también en esta misma aunque de naturaleza diversa se comprenden las Inspecciones o fiscalizaciones; que se basan en la verificación de condiciones de ejercicio de la actividad de que se trate.

Y como cierre a la policía general se encuentran las Sanciones; que atiende al elemento coactivo y represivo de esta actividad.

\section{La gestión de riesgos y la opción por el riesgo permitido ${ }^{27}$.}

El panorama antes descrito ha ido cambiando, pasando de la vieja téc-

${ }^{26}$ Ibíd., 39-40.

${ }^{27}$ Esteve Pardo, J., cit. (n. 8), pp. 10-12. También Esteve Pardo, J., Lecciones de derecho administrativo (Madrid, Marcial Pons, 2011), pp. 359-360. 
nica de policía administrativa y del orden público realizada concretamente por "cuadros" de funcionarios administrativos, a una diferente que basa su operación en la gestión de riesgos y en la opción o determinación por el riesgo permitido.

Que el riesgo se erija así en el centro de las preocupaciones del derecho ambiental exige o reclama un cambio de perspectiva y de encuadre conceptual de éste. En efecto, esta disciplina se adscribía, en sus primeros desarrollos, a la vieja policía administrativa de acuerdo a un clasificatorio y conceptos de sobra conocidos; y así, las técnicas de intervención administrativo-ambiental eran las propias de la policía administrativa: regulación, autorización, ordenación; inspecciones; y sanciones. Sin embargo, ese esquema, los conceptos y normas, están claramente desajustados a la realidad porque la policía administrativa y las técnicas de intervención tradicionales han venido operando en torno a una serie de conceptos ya no vigentes; del mismo modo que le ocurre a la disciplina matriz del derecho administrativo ${ }^{28}$.

Tradicionalmente, en cuanto a la intervención de la policía administrativa se refiere, el concepto clave era el de orden público: orden público no solamente en el ámbito de la seguridad, sino que el orden público también se extendió después al orden económico, al orden sanitario, de orden de la salubridad, de orden para el uso o la protección de recursos naturales, entre varios más.

Y este orden público es un concepto que admite un nivel cero, un nivel de pleno orden público, siendo ese el objetivo final de la policía administrativa general; siendo común a ello la idea y expresión de mantenimiento o, en su caso, restablecimiento -mucho más significativo- del orden público. El orden público, sea el que sea, en alguna situación determinada puede verse alterado -derivado de un incendio, de una infección-y se aspira por medio de sus instrumentos y herramientas a su restablecimiento, es decir, a que esa alteración del orden público se erradique por completo.

Como se ha destacado especialmente por Esteve, esta aspiración, con relación a los riesgos, es una aspiración absolutamente irreal, toda vez que no es posible aspirar a un riesgo cero, pues no existe, es inalcanzable. El riesgo cero sería posible alcanzarlo sólo y en la medida que volviéramos a un estado de naturaleza en el cual, no estaríamos afectados por los riesgos de la tecnología que nosotros desarrollamos, pero estaríamos expuestos entonces a todos los peligros naturales posibles, de mucha mayor entidad sin duda.

Con relación a los riesgos la gran decisión o la única decisión está en la opción entre riesgos, de tal manera que las decisiones en materia de riesgos y,

${ }^{28}$ En este sentido, Rojas CALderón, C., Las potestades administrativas en el derecho chileno (Santiago, Thomson Reuters LegalPublishing, 2014), pp. 139-144. 
en definitiva, todas las decisiones que se realizan en materia medioambiental y todos los debates que se plantean y que se suscitan, son debates en torno a la opción entre riesgos. En consecuencia, el debate se circunscribe o se debe circunscribir estrictamente en optar entre dos riesgos, con mayores o menores contaminaciones, con mayores o menores costos financieros, con mayores o menores afecciones a la salud o seguridad o bienes de una persona, o de un colectivo o de toda la población, en un panorama donde los factores son múltiples.

Ahora bien, esa decisión: la determinación de qué riesgos se soportan, debe ser hecha por la comunidad, por medios legitimados. Y el modo de hacerlo es a través de un ejercicio democrático de toma de decisiones en tal campo, pero al mismo tiempo, traducido en instrumentos jurídicos, que permitan objetivizar esas decisiones a través y por medio de las instancias constitucionalmente institucionalizadas de toma de decisiones. La ley, el reglamento, el procedimiento administrativo, y unos correctos los sistemas de recursos administrativos y judiciales -con unas áreas de operación claras y no difusas-, son mecanismos a través de los cuales, las decisiones se legitiman ${ }^{29}$.

En este mismo sentido Fischer, señala que existe una aparente dicotomía entre ciencia y democracia, pero que en realidad la discusión no se resuelve entre discrecionalidad técnica y desacuerdos éticos, sino que la decisión de ello concierne a las instituciones colectivas, y son ellas las encargadas de identificar, entender y tomar decisiones y acciones en torno a los riesgos ${ }^{30}$.

Luego, la idea y concepto de riesgo, así como las magnitudes que pueda alcanzar, nos separan por completo del panorama de intervención administrativa tradicional que estaba centrado en lo que son agresiones puntuales a un supuesto orden público, político, económico, sanitario, forestal, agrícola, etcétera. Porque todo este sistema que había desarrollado el derecho de intervención frente a posibles agresiones al orden público se basaba en la idea de que esas agresiones se producían al margen de la ley, es decir, que se producían infracciones legales. El sistema tradicional de policía o el sistema de control que había ideado el derecho público, era un sistema de control y, en su caso, de represión de actividades marginales, clandestinas, marcadamente contrarias a la legalidad vigente.

Pues bien, los riesgos tecnológicos generados con el desarrollo industrial y todo el desarrollo tecnológico reciente, no tienen ya como criterio central de referencia y valoración la legalidad. Los problemas del derecho ambiental

\footnotetext{
${ }^{29}$ Esteve Pardo, J., Convivir con el riesgo. La determinación del riesgo permitido, en PÉrez Alonso, E. y otros (editores), Derecho, globalización, riesgo y medio ambiente (Valencia, Tirant lo Blanch, 2012), pp. 278-279.

${ }^{30}$ Fischer, E., Risk. Regulation and Administrative Constitutionalism (Portland, Hart Publishing, 2010), p. 11.
} 
no son problemas que se planteen con relación a actuaciones clandestinas como, por ejemplo, la de un individuo que tiene una industria clandestina y que por la noche, utilizando un camión cisterna, vierte determinados residuos de manera ilegal en el curso del río Limarí o el Mapocho; sino que los problemas que se le plantean al medio ambiente son, precisamente, los que surgen de situaciones que ajustadas plenamente a la legalidad, aún así puede producir y generar riesgos, y puede producir y generar daños ambientales.

En este estado de situación, se añade un problema. Éste radica en que se está imponiendo más la referencia técnica y la referencia científica sobre lo que es la referencia jurídica; lo que genera cada vez más y más una clara disociación y desconexión entre lo que son referencias científicas y lo propio de las referencias jurídicas.

\section{Las funciones del derecho ante los riesgos ${ }^{31}$.}

Dicho lo anterior, resulta clave sostener y aclarar que las decisiones que se toman con respecto a los riesgos, incluidas las que se adoptan por las normas jurídicas y por las autoridades públicas, no son decisiones que implican la exclusión de todo riesgo, pues la tecnología nunca va a ser insípida. Son decisiones que ineludiblemente se plantean como opciones entre riesgos, optando por un riesgo u otro, o por determinado nivel de riesgo. Entonces, las decisiones jurídicas mediante normas legales, reglamentarias o de inferior nivel o derechamente decisiones administrativas singulares -actos administrativos-, son decisiones cuyo objeto es determinar el riesgo, o el nivel de riesgo por el que se opta; en definitiva, el riesgo que se acepta o riesgo permitido ${ }^{32}$.

Como viene destacándose hace tiempo ya, la cuestión sobre los riesgos, es propia de países desarrollados o en vías de desarrollo, al encontrarse estrechamente vinculada dicha cuestión con una sociedad industrial y tecnológicamente desarrollada y en constante evolución ${ }^{33}$; estado de cosas que normalmente desborda al derecho, el que en miras de respuestas eficaces y eficientes debe dejar de lado una perspectiva de operación tradicional -lenta y segura-, para dar pie a la instrumentación jurídica caracterizado por medios ágiles de respuesta, que tutelen al mismo tiempo tanto los derechos de las personas como la actividad económica y los intereses generales dentro de los cuales está claramente la tutela del medio ambiente.

En este sentido, el primer co me tid o que corresponde a los poderes públicos en relación a los riesgos, es la determinación y decisión sobre el

${ }^{31}$ Esteve Pardo, J., Derecho del medio ambiente (Madrid, Marcial Pons, 2008), pp. 53-62.

${ }^{32}$ Esteve Pardo, J., cit. (n. 28), p. 361.

${ }^{33}$ Esteve Pardo, J., cit. (n. 1), p. 107. 
riesgo que se acepta ("risk assesment"), lo que requiere de su conocimiento y valoración y que genera una referencia normativa; y el s e gu nd o co m etid o es la gestión del riesgo ("risk management") que previamente ha sido aceptado, a través de lo cual se ejerce un control sobre el riesgo, y se posibilita adoptar las medidas necesarias para su reducción, que atiende a las instancias y sujetos que desarrollan esas funciones.

De tal manera que los dos ámbitos referidos -el normativo y el de control- se erigen como centro de la regulación, gestión y control de los riesgos.

Luego, la determinación y decisión del riesgo permitido puede realizarse con carácter general o de manera particular, en virtud de la atribución que en dosis medidas y competenciales de poder jurídico - las potestades administrativas-, el ordenamiento atribuye a los órganos encargados de dicha determinación o gestión en su caso ${ }^{34}$.

Esta primera forma, se realiza a través de instrumentos normativos, como una ley base y reglamentos o normas de ese orden.

Dentro de los mismos instrumentos jurídicos, es posible distinguir entre: normas de calidad, normas de emisión, normas reguladoras de producto, normas reguladoras de procesos de producción, normas reguladoras de estándares de calidad, normas de procedimientos, normas de coordinación de políticas ambientales, normas de ordenación territorial, normas de incentivo y normas de acuerdos voluntarios; cuya naturaleza jurídica es claramente de tipo administrativa.

5. En este contexto, el marco de la normalización técnica ${ }^{35}$.

a) La normalización en general. Como se ha afirmado, la complejidad y el continuo progreso de la tecnología, ha superado con holgura las instancias y referencias públicas ordinarias; lo que en el ámbito normativo se manifiesten las referencias de esta clase ya no en normas jurídicas, sino que en las denominadas normas técnicas situadas extra muros del ordenamiento jurídico en principio ${ }^{36}$, que concreta una fijación de riesgo permitido más allá del ordenamiento jurídico y de las determinaciones de las autoridades públicas tradicionales.

Luego, en general puede definirse a la normalización (o estandarización) como el proceso destinado a la elaboración de unos elementos de referencia comunes para ordenar los diferentes comportamientos o actividades que se presentan de manera repetitiva en las relaciones sociales. Y enseguida la

\footnotetext{
${ }^{34}$ Sobre ello, Rojas Calderón, C., cit. (n. 29), pp. 41-80.

${ }^{35}$ Rojas Calderón, C., Implicancias jurídicas de la normalización técnica. Sus antecedentes, proyección y las manifestaciones para el caso de Chile. Revista de Derecho de la Universidad Católica del Norte, 16 (2009) 1, pp. 96-100 y 111-113.

${ }^{36}$ Esteve Pardo, J., cit. (n. 1), p. 108.
} 
normalización industrial es el proceso destinado al establecimiento de las normas que rigen la vida industrial, en tanto parámetros o criterios que deben ser respetados por los productos o sus fabricantes para poder ocupar un sitio en el mercado ${ }^{37}$.

Enseguida, a partir de la complejidad referida previamente -especialmente vinculada con actividades tecnológicas o industriales-, es posible afirmar que han surgido respuestas que intentan hacer frente a una actividad en donde existen intereses públicos comprometidos, como es la finalidad ambiental. Estas respuestas pueden agruparse en tres tipos: $i$ ) regulación jurídica y control directo por la Administración Pública; ii) regulación jurídica y control realizado por particulares; y iii) y normalización. Bien se sabe, ésta última alternativa es la fórmula en que los países más desarrollados han dado respuesta a las dinámicas y complejidades planteadas por la seguridad y calidad.

De esta manera, la normalización encuentra su expresión más fiel en la norma técnica ${ }^{38}$, y por ella hemos de entender una especificación técnica, que adquiere valor "normativo" en el ámbito normalizador. A su vez, las normas técnicas son susceptibles de clasificación, y según su origen se pueden distinguir entre normas internacionales y normas nacionales.

Cabe señalar -en miras de este trabajo-, que la normalización industrial surgió como una actividad completamente privada y completamente ajena al aparato orgánico administrativo, que fue cobrando relevancia en un mercado cada vez más pujante y hoy globalizado. Sin perjuicio de lo anterior, a pesar de esa naturaleza privada al inicio - tanto por sus actores como por las cuestiones que le dieron origen, basadas en la compatibilidad de componentes de piezas industriales-, se ha ido experimentando un progresivo acercamiento a intereses públicos, sobre todo atendidas las finalidades a que se encuentra vinculada. Esto ha generado también, un progresivo interés por regular públicamente dicha actividad y, por ello, un acercamiento a la consideración de esta actividad como el ejercicio de una función pública.

Lo anterior, dados los intereses y ventajas de este proceso, se producen en una triple dimensión:

i) En relación a los fabricantes de productos: en la medida que la normalización constituye la condición para el paso de una producción artesanal a una en masa; posibilita la reducción de tiempo en los procesos industriales; permite la reducción de la variedad inútil de productos; y contribuye a for-

${ }^{37}$ Álvarez García, V., Introducción a los problemas juridicos de la normalización industrial, normalización industrial y sistema de fuentes, en Revista de Administración Pública, 147 (1998), p. 311.

${ }^{38}$ TARrés Vives, M., Normas técnicas y ordenamiento jurídico (Valencia, Tirant lo Blanch, 2003), p. 232. 
talecer el prestigio de la empresa "que fabrica conforme a normas" así como la reputación de sus productos.

ii) En relación a los consumidores o usuarios: toda vez que las normas, al fijar niveles de seguridad y calidad contribuyen a protegerlos; facilitan mayor información sobre el producto y/o empresa; y al incentivar la producción en masa generan economías de escala, lo que hace productos más baratos en su adquisición.

iii) En relación al interés general, cuya protección está encomendada a los poderes públicos: pues la normalización cumple numerosos objetivos como constituir un mecanismo para la política industrial; permite conseguir una gestión racional de materias primas; contribuye al desarrollo tecnológico; posibilita la promoción de la seguridad y salud de los ciudadanos, la protección del medio ambiente y el desarrollo de la calidad de los productos industriales asegurando una progresiva mejora en la calidad de vida de las personas; contribuye a la simplificación de las relaciones económicas o comerciales internacionales al promover la utilización de un lenguaje común, así como bases contractuales y de referencias técnicas comunes; en fin, facilita la tarea de elaboración normativa de los poderes públicos, a partir de la labor realizada a propósito de normas técnicas ${ }^{39}$.

Así, la normalización es un objetivo primordial de los poderes públicos en tanto por su intermedio se accede a un instrumento que permite la defensa medioambiental, la protección de la salud, la seguridad, el derecho de los consumidores, y el fomento de la actividad industrial de calidad ${ }^{40}$.

Tradicionalmente, por el distinto ámbito de actuación de cada una de ellas, se distingue entre: normas de seguridad y normas de calidad, mismas que se pasan a revisar a continuación.

i) Las proyecciones a la seguridad y a la calidad. En primer término, las normas de seguridad atienden al ámbito de la seguridad industrial, concebida como aquella actividad que tiene por objeto la prevención y limitación de riesgos, así como la protección de accidentes y siniestros capaces de producir daños y perjuicios a las personas, flora, fauna, bienes o medioambiente, derivados de cualquier fase de la actividad industrial; se trata en efecto de un campo muy amplio, cuyas especificaciones deben desarrollarse en la normativa de cada sector o industria ${ }^{41}$.

Esta primera cuestión, es considerada núcleo fundamental de la materia de industria, en donde se incluyen las actividades destinadas a la ordenación

\footnotetext{
${ }^{39}$ Álvarez García, cit. (n. 37), p. 315.

${ }^{40}$ Carrillo Donaire, J. A., El derecho de la seguridad y de la calidad industrial (Madrid, Marcial Pons, 2000), p. 68.

${ }^{41}$ Padrós ReIG, C., Actividad administrativa y entidades colaboradoras (Madrid, Tecnos, 2001), pp. 5960.
} 
de los sectores industriales y más precisamente las actividades relacionadas con la seguridad de instalaciones y establecimientos, procesos industriales y productos. Precisamente porque comprende esas actividades, las mismas constituyen título justificativo de intervención administrativa en miras de su finalidad de salvaguarda de la salud e integridad física de las personas, lo que exige necesariamente una actividad de vigilancia sobre dicha actividad y sus resultados; y dicha actividad de vigilancia o control puede ser ejercida directamente por la Administración Pública competente en virtud de su potestad de policía administrativa general, o -más modernamente, que es lo que se sigue acá, controlar por los procedimientos de certificación de productos y procesos industriales con carácter previo a su instalación o puesta a la venta en el mercado, última circunstancia que es prevista en normas técnicas y en certificaciones realizadas por organismos privados previamente acreditados.

Sus normas tienden a regular la actividad dirigida a la prevención de los daños y la protección contra los riesgos potenciales que comprende la utilización de los productos y el funcionamiento de las instalaciones industriales; y tiene por finalidad limitar las causas que originan dichos riesgos y establecer los oportunos controles e inspecciones que permitan prevenir, detectar y, en su caso, evitar las circunstancias que pudieran dar lugar a la aparición de tales riesgos. Ejemplo de ello se encuentra en el etiquetado de especificaciones alimenticias o farmacéuticas, y las normas de seguridad en la construcción de inmuebles. En dicha virtud, la normación de la seguridad industrial, comprende la regulación pública de determinados aspectos relativos a la producción industrial, y que juega un papel fundamental en orden a asegurar la regularidad y normalidad de dicha actividades ${ }^{42}$. Y el instrumento más adecuado asegurar el cumplimiento de las condiciones de seguridad, aparte de los incentivos como subvenciones o fomentos estatales en general, se encuentra en un catálogo de infracciones administrativas normalmente presente en este tipo de regulaciones, no sólo de tipo pecuniaria, sino también la pérdida de derecho a apoyos estatales o incluso el cierre temporal o definitivo del establecimiento industrial de que se trate $e^{43}$.

ii) Y en un segundo término, las normas de calidad, atienden a la calidad industrial, concebida como aquella actividad que trata de conseguir la continua mejora de los procesos industriales, en miras de la mayor adecuación posible entre sus propiedades, características y las necesidades que pretenden satisfacer ${ }^{44}$. Esta cuestión comprende, evidentemente, la creciente importancia de las disposiciones referentes a normalización, homologación

${ }^{42}$ Carrillo Donaire, J. A., cit. (n. 40), p. 25.

${ }^{43}$ Bermejo Vera, J. et al. derecho administrativo. Parte especial (Cizur Menor, Thomson Civitas, 2005), p. 973.

${ }^{44}$ Ibíd., pp. 973-974. 
y certificación, desarrolladas por entidades colaboradoras o por laboratorios estrictamente privados. En virtud de ella, es posible obtener un reconocimiento jurídico-público lo realizado por un conjunto de agentes que no toman como base de su actuación lo previsto en los reglamentos de seguridad dictados por la Administración, sino lo que se contiene en normas técnicas elaboradas por organismos nacionales e internacionales de normalización ${ }^{45} ; \mathrm{y}$ ello ocurre como consecuencia de la cada vez mayor concurrencia e internacionalización de los mercados, la mejora de la competitividad de las empresas, y las progresivas exigencias de calidad por parte de los receptores finales de los productos; y en tal sentido el concepto de calidad se ha convertido en un crisol de confluencia de la excelencia productiva que, al mismo tiempo, se transforma en un factor diferenciador en el mercado.

Luego, desde el punto de vista de la técnica jurídica, la calidad industrial se asienta sobre la base de dos instrumentos: la normalización y la certificación; y sobre un principio básico: la voluntariedad de su cumplimiento. Ambos aspectos, importan actividades complementarias e inescindibles.

La normalización y la certificación de calidad son actividades utilizadas en casi todos los ámbitos de la vida económica y ello, es considerado hoy, dentro de las inversiones que debe realizar una empresa y ya no un gasto. Así tanto la supervivencia de una empresa, como la posible incorporación a nuevos mercados en el ámbito de una economía comercialmente abierta, está ligada a la mejora de su competitividad mediante la implantación de técnicas de calidad industrial; y, por ello, la normalización industrial y la certificación voluntaria son elementos imprescindibles en el marco de un sistema industrial competitivo ${ }^{46}$.

Por consiguiente, en este ámbito, donde la normalización se concreta en el establecimiento de documentos de referencia que aporten soluciones a problemas no sólo técnicos, sino que también comerciales que conciernen a productos, bienes y servicios en las relaciones entre los agentes económicos, científicos y sociales ${ }^{47}$; se hace preciso, enseguida, que se certifique o compruebe la sujeción de dichos sistemas, procesos, equipos y productos a los requisitos y especificaciones técnicas referenciales de calidad, establecidos en normas técnicas voluntarias, llevado a cabo por una entidad independiente, cuya competencia técnica acreditadora ha sido previamente habilitada.

\footnotetext{
${ }^{45}$ TARrés Vives, M, cit. (n. 38), pp. 406-407.

${ }^{46}$ Carrillo Donaire, J. A., cit. (n. 40), 3437.

${ }^{47}$ Tarrés Vives, M., cit. (n. 38), p. 231.
} 


\section{LA GESTIÓN DE RIESGOS Y, EN ESPECIAL, LA CERTIFICACIÓN AMBIENTAL}

\section{El medio habitual de gestión de riesgos.}

La gestión o administración de los riesgos, se realiza normalmente mediante actos administrativos de autorización para la realización de actividades fundamentalmente productivas, los que requieren necesariamente de un procedimiento administrativo. Ejemplo concreto de ello, son las resoluciones de calificación ambiental.

En esta parte, conviene señalar que claramente el Servicio de Evaluación Ambiental comprende un procedimiento administrativo destinado a obtener permisos o autorizaciones ambientales, es decir, actos evidentemente administrativos ${ }^{48}$. De este modo, dicho servicio es uno más de los instrumentos de gestión o protección ambiental contemplados en la ley; y, al mismo tiempo, es concreción de actividad de gestión de riesgos por medio de la autorización de actividad de particulares (la vieja técnica de la policía administrativa).

A través suyo se establecen, comprensivamente bajo un solo arco de posibilidades de intervención administrativa, regulaciones particulares (concretadas en la resolución de calificación ambiental) que contiene obligaciones y prohibiciones, siendo la misma es una autorización o permiso administrativo en sí para el ejercicio de una actividad, sujeta a procedimientos administrativo.

Adicionalmente, durante su "vida" se encuentra sujeta a permanentes inspecciones de cumplimiento, que constituyen la actividad de fiscalización ambiental propiamente tal; $y$ en caso de infracción, recibe sanciones de naturaleza administrativa. Y como cualquier poder jurídico-administrativo, debe estar contenida en una ley habilitante que permita tanto la configuración como la organización del ejercicio de dicha potestad inspectiva, sobre todo considerando las restricciones a la libertad, la imposiciónd e obligacionescargas de entrega o provisión de información bajo unas condiciones determinadas con miras de la comprobación de una determinada situación de hecho en relación con la norma -en principio- jurídca del sector que ordena la situación controlada ${ }^{49}$.

En fin, al respecto es posible señalar que la legislación chilena, ha reconocido este sistema como instrumento preventivo de control sobre proyectos

\footnotetext{
${ }^{48}$ Bermúdez Soto, J., cit. (n. 13), p. 35 y Bermúdez Soto, J., cit. (n. 14), p. 36.

${ }^{49}$ Canals i Ametller, D., El ejercicio de funciones públicas por entidades privadas colaboradoras de la Administración. Galán Galán, A. - Prieto Romero, C. (directores), El ejercicio de funciones públicas por entidades privadas colaboradoras de la Administración (Madrid, Huygens, 2010), pp. 27-28.
} 
determinados, lo que redunda en una limitación y un aseguramiento al mismo tiempo para la realización de determinadas actividades económicas ${ }^{50}$.

2. El fenómeno, no tan reciente, del control técnico por particulares con efectos públicos ${ }^{51}$.

Otro modo de gestión del riesgo, encargado del control sobre el mismo es por medio de la actividad que ejercen entidades privadas colaboradoras de la Administración pública en este campo. Las mismas completan esta actividad al controlar el cumplimiento de las condiciones de la autorización ambiental integrada.

Esto, por lo demás, ha sido descrito por Bermúdez muy acertadamente como una manifestación del principio de co o per a ción -parte de los principios del derecho ambiental-, en virtud del reconocimiento de entidades certificadoras $^{52}$, que coadyuvan en la actividad fiscalizadora.

Preliminarmente, resulta pertinente señalar que esta figura se inserta dentro de una realidad general evidente, aun cuando no ha sido suficientemente destacada en Chile, consistente en la irrupción en las últimas dos o tres décadas de entidades colaboradoras de la Administración Pública, la que se enmarca dentro de la categoría jurídica aun indefinida y general del "ejercicio privado de funciones públicas" consideradas como cualquier forma de actividad de la que derive una actuación de fin o con efectos públicos, realizadas por un sujeto que no tiene la cualidad de órgano público ${ }^{53}$. Esto, como se ha señalado, constituye un fenómeno general que tiene múltiples aristas, manifestaciones y que genera problemáticas no suficientemente perfiladas ${ }^{54}$.

\footnotetext{
${ }^{50}$ Bermúdez Soto, J. cit. (n. 13), p. 190; y Bermúdez Soto, J., cit. (n. 14), p. 263.

${ }^{51}$ Hay una famosa frase de Deng Xiaoping (1904 1997), que sintetiza esta idea: "No importa que el gato sea blanco o sea negro. Mientras cace ratones, es un buen gato".

${ }^{52}$ Bermúdez Soto, J. cit. (n. 14), pp. 52-54.

${ }^{53}$ Canals i Ametller, D., El ejercicio por particulares de funciones de autoridad. Control inspección y certificación (Granada, Comares, 2003), p. 273. Claramente, hasta donde se ha revisado, es la mejor obra sobre la materia.

${ }^{54}$ En España se ha destacado, aparte de los autores antes citados, especialmente por Esteve Pardo, J. Autorregulación. Génesis y efectos (Cizur Menor, Aranzadi, 2002), pp. 50 101; Tarrés Vives, M., cit. (n. 38), pp. 136-201; y Darnaculleta I GarDELla, M., Autorregulación y derecho público, la autorregulación regulada (Madrid, Marcial Pons, 2005), pp. 101140 y 416-443; en Chile destacan a su turno: Rojas CAlderón, C. Los organismos autónomos y la Administración del Estado, en CORDERo Quinzacara, E. (coordinador), Estudios sobre la Ley Orgánica Constitucional de Bases generales de la Administración del Estado (Santiago, Ediciones Universidad de Antofagasta, 2008), pp. 147-154; Rojas Calderón, C., Alcance y aplicabilidad de la nulidad administrativa a los actos emanados de particulares en el ejercicio de funciones públicas, en FERRAda BórQuez (editor), La nulidad de los actos administrativos en
} 
Pues bien, la protección ambiental no depende solamente de unos adecuados y bien estructurados instrumentos de normación jurídico-ambiental, otros que provienen de la gestión ambiental habitual, como pueden ser todos los que surgen del Servicio de Evaluación Ambiental, que operan al inicio, sino que es preciso sumarle también pertinentes instrumentos de inspección o fiscalización que concentren su acción en el cumplimiento de la normativa ambiental general, o en el cumplimiento de los instrumentos que autorizan una actividad (contenido en la resolución de calificación ambiental correspondiente), cuestión altamente compleja por las variables técnicas, geográficas, económicas, entre muchas otras, que implica tal tarea.

Ante ello surge como otro instrumento jurídico -complementario si se quiere-, la actividad de certificación que opera sobre parámetros técnicos y objetivos, de alta complejidad, y que requiere unos conocimientos especializados. En virtud de todo ello, y a través de la sanción jurídica adecuada de esa actividad -lo que implica que no puede ser cualquiera-, el Estado reconoce la competencia técnica independencia e idoneidad moral de una entidad privada para que ella de fe del cumplimiento de ciertas condiciones ambientales, de un producto, proceso o establecimiento.

En este sentido, la entidad certificadora u organismo certificador puede definirse como la que es reconocida o acreditada por la Administración Pública en virtud de su grado de conocimiento científico o técnico, idoneidad ética y profesional, y su independencia e imparcialidad ${ }^{55}$.

Así pues, al carecer de legitimación en un primer momento, es ineludible establecer mecanismos y medios precisos, determinados y efectivos de atribución a estos sujetos y organizaciones privadas de tales funciones públicas, lo que implica también la supervisión del ejercicio de dichas funciones de control técnico ${ }^{56}$. Habrá, por consiguiente que establecer mecanismos de apoderamiento o reconocimiento, unos procedimientos determinados, y unos sistemas de control de sus actividades e impugnación de sus decisiones (en tanto tengan efectos jurídico-públicos).

\section{La configuración jurídica de la certificación ambiental.}

Lo explicado hasta ahora se encuentra con la institucionalidad ambiental, en la medida que la certificación es un instrumento reconocido por el

el derecho chileno (Santiago, Thomson Reuters LegalPublishing, 2013), pp. 79-124; y Rajevic Mosler, E., La privatización de las funciones públicas en el urbanismo y la vivienda, en Bockang Hola, G. - Vergara Blanco, A. (coordinadores), Público $y$ privado en el derecho administrativo (Santiago, Thomson Reuters LegalPublishing, 2014), pp. 221-230.

${ }^{55}$ Bermúdez Soto, J., cit. (n. 14), p. 54.

${ }^{56}$ Esteve Pardo (n. 1), p. 124. 
ordenamiento jurídico-ambiental para llevar adelante la actividad de control que es parte de la gestión de riesgos asociados.

Por ella, a partir de lo revisado, debemos entender genéricamente que la certificación es la declaración contenida en un documento que un determinado producto o proceso o empresa o establecimiento, cumple con los requisitos establecidos en una norma técnica ${ }^{57}$.

Ahora, cuando se trata de lacertificación a mbiental, la declaración recaerá sobre el carácter sustentable o menos dañoso para el medio ambiente que posee el producto, proceso o establecimiento ${ }^{58}$.

Conviene en esta parte diferenciar una certificación voluntaria, que se asocia a la verificación de las cualidades ambientales o de sustentabilidad de un producto, proceso o establecimiento; $y$ que genera una certificación muy apreciada en el mercado, pero que además sirve a efectos de facilitar los procedimientos administrativos con carácter de autorización, pues constituyen prueba del cumplimiento de todo o parte de la normativa ambiental aplicable. Y por otro lado, se reconoce la certificación obligatoria, normalmente asociada a procesos o productos (de productos eléctricos, de determinados alimentos, de licores, entre muchos otros $)^{59}$.

Pues bien, esa tarea que, en principio, aparece como una actividad en principio estatal -atendido que constituye materialmente una actividad de inspección como técnica de control, lo que constituye ejercicio de una función pública en sentido estricto-, pero que en realidad es realizada mayoritariamente por privados que cumplen esta función pública certificadora; constituyendo esta situación un claro caso del fenómeno a que se ha hecho referencia anteriormente, y que constituyen una parte significativa de la acción de fiscalización ambiental, de naturaleza material y eminentemente administrativa.

Su regulación jurídica se revisa someramente a continuación.

a) En la Ley de bases generales del medio ambiente. De acuerdo a lo establecido en la ley misma, actualmente existe una condición para la verificación ambiental a través de la acción de la Superintendencia del Medio Ambiente, lo que se concreta en este nivel normativo a través del artículo 18 ter.

Conforme con lo anterior, en el marco de los proyectos que presentan una "declaración de impacto ambiental", los titulares de éstos pueden incluir a su costo, el compromiso de someterse a un proceso de evaluación y certificación de conformidad, respecto del cumplimiento de la normativa ambiental

\footnotetext{
${ }^{57}$ Bermúdez Soto, J., cit. (n. 13), p. 218.

${ }^{58}$ Bermúdez Soto J., cit. (n. 14), p. 325.

${ }^{59}$ Ibíd., p. 326.
} 
aplicable y de las condiciones sobre las cuales se califique favorablemente el proyecto o actividad.

Para tales efectos, la Superintendencia del Medio Ambiente debe llevar un registro de las personas naturales y jurídicas acreditadas, que realicen la evaluación y certificación de conformidad de las resoluciones de calificación ambiental. Los requisitos, condiciones y procedimientos necesarios para su administración y funcionamiento de estas entidades se determinará en vía reglamentaria.

Adicionalmente el artículo 18 quáter abunda sobre ello en otro sentido. $\mathrm{Al}$ respecto se establece que si el titular del proyecto es una empresa que según la ley califica como de menor tamaño y debe presentar una declaración de impacto ambiental podrá comprometer a su costo, someterse a un proceso de evaluación y certificación de conformidad, respecto del cumplimiento de la normativa ambiental aplicable al proyecto o actividad.

Esto es lo establecido en la ley matriz del sector.

b) En la Ley orgánica de la Superintendencia del Medio Ambiente. Ahora bien, la Ley orgánica de la Superintendencia del Medio Ambiente desarrolla este aspecto más específicamente.

$\mathrm{Al}$ respecto se establece en su artículo $3^{\circ}$ letra c) que la Superintendencia del Medio Ambiente puede contratar labores de inspección, verificación, mediciones y análisis del cumplimientos de instrumentos de gestión ambiental, a terceros idóneos debidamente certificados,

Asimismo, en la letra p) del citado artículo, se dispone que la Superintendencia administrará un mecanismo de evaluación y certificación de conformidad, respecto de la normativa ambiental aplicable y de las condiciones de una autorización de funcionamiento ambiental.

En específico la disposición indicada señala que la Superintendencia tendrá las siguientes atribuciones y funciones ${ }^{60}:$ " $\mathrm{p}$ ) Administrar un mecanismo de evaluación y certificación de conformidad, respecto de la normativa ambiental aplicable y del cumplimiento de las condiciones de una autorización defuncionamiento ambiental. / Para estos efectos, la Superintendencia administrará un sistema de acreditación de personas naturales y juridicas que realicen estas evaluaciones y certificaciones. El Reglamento determinará los requisitos, condiciones y procedimientos necesarios para su administración y funcionamiento, el que deberá a lo menos considerar la incompatibilidad absoluta entre el ejercicio de labores de evaluación y certificación y las de consultoría para la elaboración de Declaraciones o Estudios de Impacto ambiental, así como los requisitos minimos de conocimiento, la experiencia calificada, de a lo menos 3 años, en materias relacionadas, los procedimientos de examen o verificación

${ }^{60}$ Que no son más, ni menos, que potestades administrativas en definitiva. 
de antecedentes, personal idóneo e infraestructura y equipamiento suficiente para desarrollar las labores solicitadas. / Las infracciones a las obligaciones derivadas de este sistema, asi como la de las personas acreditadas se sancionará de conformidad a lo señalado en el título III de la presente ley".

En consecuencia, el sustrato normativo queda claro, y a éste y los que se dicten en conformidad al mismo, debe estarse dicha actividad.

c) Reglamento de entidades técnicas. Como se ha serñalado, la Ley de bases generales y la Ley orgánica de la Superintendencia del Medio Ambiente establecen un sistema de evaluación y certificación de conformidad, por lo que la Superintendencia llevará un registro de las personas naturales y jurídicas acreditadas que pueden desarrollar dichas labores.

Luego, teniendo a la vista dichas disposiciones, la Superintendencia emitió la Resolución exenta № 37, de 15 de enero de 2013, donde se fijaron normas generales sobre entidades de inspección ambiental y validez de reportes, en especial para mantener de forma transitoria como entidades de inspección ambiental, aquellas que ya estaba acreditadas, certificadas o autorizadas ante otra administración pública, y de este modo - hasta la dictación de los reglamentos-, mantener funcionando el sistema.

Pero efectivamente, las funciones y atribuciones de la Superintendencia, deben ser ejecutadas a través de la entrada en vigencia de los respectivos reglamentos de entidades técnicas de la Superintendencia, que se han emitido y pasan a ser analizados ${ }^{61}$.

i) Decreto supremo $\mathrm{N}^{\circ} 38 / 2013$, del Ministerio del Medio Ambiente: Reglamento de entidades técnicas de fiscalización ambiental.

Esta normativa regula las entidades de fiscalización ambiental que realizan actividades de inspección, verificación, mediciones y análisis.

A través del Reglamento aludido se regulan los requisitos que debe cumplir un solicitante para ser autorizado por la Superintendencia, como entidad técnica de fiscalización ambiental o inspector ambiental.

Asimismo, se fija el procedimiento a través del cual la Superintendencia debe verificara que un solicitante cumpla con los requisitos para ser autorizado como entidad técnica de fiscalización ambiental o como Inspector ambiental, y la incorporación de ambos al Registro, una vez autorizados, así como la renovación, suspensión y revocación de la autorización.

Del mismo modo, se establecen las obligaciones y los conflictos de intereses de la entidad técnica de fiscalización ambiental y del Inspector ambiental para desarrollar actividades de fiscalización ambiental, así como su control y supervigilancia.

En fin, se especifican las actividades de fiscalización ambiental y los requi-

${ }^{61}$ Ambos publicados en el Diario Oficial de 18 de marzo de 2014. 
sitos mínimos de los certificados que se otorguen como resultado de ellas, que debe comprender: inspección ambiental en terreno, examen de información o verificación, y mediciones o análisis incluso muestreo.

El resultado de su actividad se materializa en que la entidad técnica de fiscalización ambiental deberá entregar a los titulares de proyectos, actividades o fuentes referidos en el artículo 21 del Reglamento, un certificado que debe dar cuenta de las actividades de fiscalización ambiental realizadas.

ii) Decreto supremo $\mathrm{N}^{\circ}$ 39/2013, del Ministerio del Medio Ambiente: Reglamento de entidades técnicas de certificación ambiental.

A través de éste se reglamentan a las entidades técnicas, ahora de certificación ambiental, que realizan actividades de evaluación y certificación de conformidad ambiental.

Los objetivos del Reglamento son los de establecer los requisitos que debe cumplir un solicitante para ser autorizado por la Superintendencia como entidad técnica de certificación ambiental o como evaluador de conformidad ambiental.

Igual que en el caso anterior, se establece el procedimiento a través del cual la Superintendencia debe verificar que un solicitante cumple con los requisitos para ser autorizado como entidad técnica de certificación ambiental o como evaluador de conformidad ambiental, y la incorporación de ambos al Registro, una vez autorizados, así como la renovación, suspensión y revocación de la autorización concedida.

También se establecen las obligaciones y la regulación sobre conflictos de intereses de la entidad técnica de certificación ambiental y del evaluador de conformidad ambiental para desarrollar actividades de evaluación y certificación ambiental, así como su control y supervigilancia respectivamente.

Por último, se regulan las actividades de evaluación y certificación de conformidad ambiental, el alcance del certificado y los requisitos necesarios para su otorgamiento. Esto mismo debe comprender: una identificación de todos y cada uno de los aspectos de la normativa ambiental y/o de las condiciones de la autorización de funcionamiento ambiental objetos de la labor de certificación ambiental; los resultados de las actividades de evaluación de conformidad ambiental y el período durante el cual se realizaron; y la emisión del certificado, si procede.

Igualmente que para el caso anterior, el resultado de su actividad se materializa en que la entidad técnica de certificación ambiental debe emitir, siempre que sea procedente, un certificado que debe dar cuenta de la conformidad del cumplimiento de la normativa ambiental aplicable y las condiciones de autorización de funcionamiento ambiental a los proyectos, sistemas, actividades o fuentes correspondientes establecidas en el artículo 19 del Reglamento. 
En fin, de especial importancia es el artículo 24 del Reglamento que señala los efectos del certificado, disponiendo que éste constituirá prueba suficiente de cumplimiento de la normativa ambiental y condiciones de autorización de funcionamiento ambiental correspondientes. Por lo mismo, no se puede iniciar procedimiento sancionatorio por los hechos que comprenda la certificación.

Con ello, se sellan los efectos claramente públicos de esta certificación realizada por el sujeto autorizado.

\section{Caracterización general de las entidades técnicas colaboradoras a nivel ambiental.}

Resulta por consiguiente, a partir de lo revisado inmediatamente antes y conectándolo debidamente con lo visto en las partes previas del trabajo, decir algo sobre estas entidades.

En primer término, señalar que las entidades colaboradoras de fiscalización, verificación y de certificación ambiental, tienen carácter o naturaleza jurídico-privada; especializadas en su campo concreto, con material y personal técnicamente experto, manteniendo una relación estable de la Administración Pública y esta colaboración resuelta del sistema registral que comprende un sistema de evaluación y certificación de sus medios y personal tanto al inicio como durante su vigencia.

En s egundo orden, es preciso sostener que la acreditación es lo que constituye el título habilitante de esta actividad ${ }^{62}$. En efecto, los títulos habilitantes tradicionales como la autorización y la concesión administrativa, resultan en todo caso inoperantes a los casos de intervención de entidades colaboradoras; y por ende, la acreditación como novel forma de para atribuir funciones públicas a entidades colaboradoras es la fórmula jurídica que resulta pertinente. $Y$ se entiende por tal, la resolución administrativa mediante la cual se certifica que una determinada entidad o agente cumple requisitos relativos a capacidad, idoneidad técnica, financiera y de medios para cumplir con objetividad funciones de control, inspección y certificación que son aquellas que hemos revisado.

En fin, en te r cer lugar, cabe hacer presente la endeble configuración de la juridicidad a partir de los reenvíos sobre todo a normas técnicas, a propósito de lo controlable, lo que puede generar y genera varios problemas ${ }^{63}$. Uno de ellos, resulta de la proyección y concreción a un nivel jurídico, teniendo vinculación esta clase de normativas técnicas con las propiamente jurídicas, en la medida que algunas de estas normas técnicas pasan a ser

\footnotetext{
${ }^{62}$ Canals (n. 49), pp. 42-44.

${ }^{63}$ Ibíd., 4447.
} 
exigibles jurídicamente por diversos medios propios de remisión normativa sobre todo los que, por reenvío, generan una exigibilidad u obligatoriedad jurídica de esta clase de normas basadas en parámetros técnicos, fijadas por organismos internacionales con correlación nacional; lo que puede generar diversos problemas adicionales uno de los cuales es el de la des-densificación de la norma jurídica aplicable al sector, ni qué decir de la ley, sustituida por un entramado de normas técnicas a los cuales se remiten sólo en la faz procedimental las normas jurídicas en esta clase de operaciones y actividades, y que sustantivamente pertenecen a un mundo no jurídico pero con efectos incontrovertiblemente públicos. Y otro, es el escaso y tangencial control jurídico de esta clase de actividades, las que en cuestiones tan sensibles y cotidianas como la seguridad en la realización de actividades industriales, la calidad de las mismas y de sus productos, o el cumplimiento de estándares ambientales a actividades de por sí altamente riesgosas, se sostiene bajo criterios exclusivamente técnicos a pesar que lo que se pone en juego son bienes jurídicos -las más de las veces- muy relevantes.

Para el caso analizado, más allá de las regulaciones reglamentarias o por vía contractual (convenio), el sistema tal cual está es altamente insuficiente a la permeabilidad por insuficiencia de la estructura jurídica, por lo que su real eficacia aun debe probarse.

\section{CONCLUSIONES}

$\mathrm{Al}$ finalizar este trabajo es posible llegar a las siguientes conclusiones:

$1^{\circ}$ La cuestión acerca de los riesgos tiene desde un punto de vista fáctico, un origen esencialmente tecnológico, por lo que resuelta esencial en la vida del hombre y vinculado a las decisiones humanas, por lo mismo, somos responsables por ellos. Para ellos existe una disciplina -la del derecho ambiental-, cuya finalidad (entre varias otras) es la de proveer los instrumentos pertinentes para decidir en la incertidumbre científica.

$2^{\circ}$ Para analizar dicha realidad, el derecho en general propone distintos enfoques disciplinarios. La que interesa a este trabajo, ha considerado al derecho ambiental como disciplina caracterizada esencialmente a partir de sus instrumentos por medio de los cuales se operativiza, de naturaleza jurídico-administrativa. Y aquello se realiza bajo una idea ordinamental, única a través de la cual es posible sostener todas las instituciones jurídicas autónomas o relacionadas.

El mismo se estructura en unos órdenes normativos complejos concretados en la Constitución política, en la Ley de Bases generales del Medio Ambiente y leyes especiales, para concluir en instrumentos normativos de orden reglamentario y de "soft law" que le dan vida, desarrollan y particularizan. 
$3^{\circ}$ Luego, a partir de la explicación acerca de las técnicas de intervención administrativa tradicionales, hoy claramente superadas en lo que dice relación con el orden ambiental surge concreta y claramente una actividad asociada a los riesgos.

Donde, por un lado, corresponde la determinación y decisión de los riesgos que se aceptan, tanto en un nivel abstracto como en uno concreto para cada proyecto, y que se manifiestan en referencias normativas específicas como normas de calidad, de emisión y resoluciones de calificación ambiental. Esto se completa por un conjunto de disposiciones de origen industrial -las normas técnicas- las que juegan prácticamente en el mismo orden (fácticamente) que las estrictamente jurídicas, lo que ha generado una serie de problemas como son la des-densificación del orden jurídico y la legalidad así como la legitimidad e dichos instrumentos.

Y por otro, corresponde la gestión del riesgo que previamente se ha aceptado.

$4^{\circ}$ En fin, en lo relativos a la gestión de riesgos, esto se produce por dos vías ya asentadas: la fiscalización ambiental a través de la administración pública sectorial o por medio de entidades privadas colaboradoras de la fiscalización o verificación ambiental; y el control ambiental a través de la certificación.

Respecto de las entidades de fiscalización y de certificación ambiental, éstas tienen naturaleza jurídico-privada, registrando en la acreditación el título habilitante de su actividad. Y las mismas son resultado de la aplicación del principio de cooperación en el cumplimiento de tareas públicas, medio legal y legítimo de satisfacción de necesidades públicas, que tiene una configuración legal y específicamente reglamentaria.

Sólo se observa que respecto de la certificación ambiental, si bien no le falta legalidad ni legitimidad al estar configurada del mismo modos que la primera, sí es una cuestión diferente, más potente a efectos jurídico-públicos; ello pues lo que hacen es dar cuenta de una conformidad, sea en el cumplimiento de normativas ambientales, sea en condiciones de funcionamiento ambiental de proyectos, pasando a ser hasta cuando dure su acreditación, la autoridad ambiental de esta área de actividad.

\section{BiBLIOGRAFÍA}

Álvarez García, V., Introducción a los problemas jurídicos de la normalización industrial, normalización industrial y sistema de fuentes, en Revista de Administración Pública, 147 (1998).

Bermejo Vera, J.y otros, Derecho administrativo. Parte especial (Cizur Menor, Thomson - Civitas, 2005). 
Bermúdez Soto, J. Fundamentos de derecho ambiental (2a edición, Valparaíso, Ediciones Universitarias de Valparaíso, 2014).

Bermúdez Soto, J., Código de Medio Ambiente (Santiago, LegalPublishing, 2007).

Bermúdez Soto, J., Fundamentos de derecho ambiental (Valparaíso, Ediciones Universitarias de Valparaíso, 2007).

Canals i Ametller, D., El ejercicio de funciones públicas por entidades privadas colaboradoras de la Administración.

Canals i Ametller, D., El ejercicio porparticulares de funciones de autoridad. Control inspección y certificación (Granada, Comares, 2003).

Carrillo Donaire, J. A., El derecho de la seguridady de la calidad industrial (Madrid, Marcial Pons, 2000).

Cordero Vega, L. La supletoriedad en la Ley de bases de procedimiento administrativo, en AA. VV., Acto y procedimiento administrativo. Actas de las Segundas Jornadas de Derecho Administrativo (Valparaíso, Ediciones Universitarias de Valparaíso, 2007).

Darnaculleta i Gardella, M., Autorregulación y derecho público. La autorregulación regulada (Madrid, Marcial Pons, 2005).

Esteve Pardo, J. - Tejada Palacios, J., Ciencia y derecho. La nueva división de poderes (Madrid, Fundación Coloquio Jurídico Europeo, 2013).

Esteve Pardo, J., Autorregulación. Génesis y efectos (Cizur Menor, Aranzadi, 2002).

Esteve Pardo, J., Convivir con el riesgo. La determinación del riesgo permitido, en PÉREZ Alonso, E. y otros (editores), Derecho, globalización, riesgo y medio ambiente (Valencia, Tirant lo Blanch, 2012).

Esteve Pardo, J., Derecho del medio ambiente (Madrid, Marcial Pons, 2008).

EsteVe PARDo, J., El derecho del medio ambiente como derecho de decisión y gestión de riesgos, en Revista Electrónica de derecho de la Universidad de La Rioja, 4 (2012).

Esteve Pardo, J., El desconcierto del Leviatán. Política y derecho ante las incertidumbres de la ciencia (Madrid, Marcial Pons, 2009)

Esteve Pardo, J., Lecciones de derecho administrativo. (Madrid, Marcial Pons, 2011). Esteve Pardo, J., Técnica, riesgo y derecho (Barcelona, Ariel, 1999).

Fischer, E., Risk. Regulation and Administrative Constitutionalism (Portland, Hart Publishing, 2010).

Fischioff, B. - Kadvany, J., Riesgo, una breve introducción (traducción de P. Ventura, Madrid, Alianza Editorial, 2013).

Galán Galán, A. - Prieto Romero, C. (directores), El ejercicio de funciones públicas por entidades privadas colaboradoras de la Administración (Madrid, Huygens, 2010).

GonzÁlez NAVARro, F., La teoría general de sistemas como matriz disciplinar y como método jurídico en Persona y Derecho, 21 (1989).

Guzmán Rosen, R., La regulación constitucional del ambiente en Chile. Aspectos sustantivos y adjetivos. Historia, doctrina y jurisprudencia (Santiago, Abeledo Perrot, 2010).

Kunn, T. S., La estructura de las revoluciones cientificas (traducción de A. Costín. Santiago, Fondo de Cultura Económica, 2000).

Martínez García, J. I., Pensar el riesgo. En diálogo con Luhman, en Pérez Alonso, E. y otros (editores), Derecho, globalización, riesgo y medio ambiente (Valencia, Tirant lo Blanch, 2012).

May, S., Nuevos riesgos, seguridady prevención, sobre la transformación del Estado moderno y su forma de actuación jurídica, en PÉrez Alonso, E. y otros (editores), Derecho, globalización, riesgo y medio ambiente (Valencia, Tirant lo Blanch, 2012). 
Molero Manglano, C., La supletoriedad del derecho común en el derecho del trabajo (Madrid, Instituto de Estudios Políticos, 1975).

Moya Marchi, F., El principio de precaución. Un estudio sobre el modelo europeo de control de riesgo (Santiago, Thomson Reuters - LegalPublishing, 2014).

PAdrós Reig, C., Actividad administrativa y entidades colaboradoras (Madrid, Tecnos, 2001).

RAJEVIC MosLER, E., La privatización de las funcionespúblicas en el urbanismo y la vivienda, en Bockang Hola, G. - Vergara Blanco, A. (editores.), Público y privado en el derecho administrativo (Santiago, Thomson Reuters - LegalPublishing, 2014).

Rojas Calderón, C., Alcance y aplicabilidad de la nulidad administrativa a los actos emanados departiculares en el ejercicio de funciones públicas, en FERRADA BórQUEZ (editor), La nulidad de los actos administrativos en el derecho chileno (Santiago, Thomson Reuters - Legal Publishing, 2013)

Rojas Calderón, C., Implicancias jurídicas de la normalización técnica. Sus antecedentes, proyección y las manifestaciones para el caso de Chile, en Revista de Drecho de la Universidad Católica del Norte, 16 (2009) 1.

Rojas Calderón, C., Las potestades administrativas en el derecho chileno (Santiago, Thomson Reuters - LegalPublishing, 2014).

Rojas Calderón, C., Los organismos autónomos y la Administración del Estado, en Cordero Quinzacara, E. (editor), Estudios sobre la Ley Orgánica Constitucional de Bases generales de la Administración del Estado (Santiago, Ediciones Universidad de Antofagasta, 2008).

Schmidt-Assmann, E., La teoría general del derecho administrativo como sistema (traducción de M. Bacigalupo y otros. Madrid, Marcial Pons, 2003).

Sunstein, C. Riesgo y razón, seguridad, ley y medio ambiente (traducción de J. M. Lebrón, Buenos Aires, Katz, 2006).

Tarrés Vives, M., Normas técnicas y ordenamiento jurídico (Valencia, Tirant lo Blanch, 2003).

Varela del Solar, J., Derecho ambiental como derecho público. Instrumentos de la politica ambiental, en Actualidad Jurídica, 22 (2010).

Vergara Blanco, A., El derecho administrativo como sistema autónomo. El mito del Código Civil como "derecho común" (Santiago, Abeledo Perrot, 2010).

Vergara Blanco, A., Principios y sistema del derecho minero (Santiago, Editorial Jurídica de Chile, 1989).

Villar Ezcurra, J. L., Derecho administrativo especial (Madrid, Civitas, 1999). 